\title{
Short interposition grafting for dialysis-access steal syndrome treatment
}

\author{
Spyros Papadoulas, ${ }^{1}$ Francesk Mulita (D) ,' ${ }^{2}$ Theoni Theodoropoulou, ${ }^{2}$ \\ Periklis Dousdampanis ${ }^{3}$
}

'Department of Vascular Surgery, University General Hospital of Patras Holy Mary the Help, Patras, Greece ${ }^{2}$ Department of General Surgery, University General Hospital of Patras Holy Mary the Help, Patras, Greece

${ }^{3}$ Department of Nephrology, Hemodialysis Unit Kyanos Stavros Patras, Patras, Greece

\section{Correspondence to}

Francesk Mulita;

oknarfmulita@hotmail.com

Accepted 27 January 2022

\section{DESCRIPTION}

A 60-year-old man on chronic haemodialysis presented with access-related severe ischemia of the hand 4 years after the creation of a left brachiocephalic arteriovenous fistula. The fingers were painful, he was pale, and skin ulceration was evident on the thumb. Concomitant diseases included arterial hypertension and diabetes. Doppler signals were severely attenuated in the forearm arteries but returned to normal after digital compression of the fistula. He underwent colour duplex examination, which revealed brachial artery flow of $2600 \mathrm{~mL} / \mathrm{min}$. The anastomosis was $8 \mathrm{~mm}$ wide, and the diameter of the proximal cephalic vein was approximately $1.5 \mathrm{~cm}$. A diagnosis of access-related steal syndrome (grade 4a) due to hyperfunctioning brachiocephalic fistula was made. Digital subtraction angiography (DSA) ruled out the presence of arterial stenoses proximal to the fistula that could affect inflow. In addition, no stenoses were detected distally that could increase peripheral resistance. We performed ligation of a major cephalic side branch to restrict overflow from the fistula, but without apparent benefit. We then subjected the patient to a more invasive procedure to restrict flow. Under local anaesthesia, we inserted a short expanded polytetrafluoroethylene (ePTFE) graft (Gore Intering) with a diameter of $6 \mathrm{~mm}$ and a length of $3 \mathrm{~cm}$ extending $1 \mathrm{~cm}$ beyond the anastomosis (figure $1 \mathrm{~A}, \mathrm{~B}$ ). Because of the discrepancy
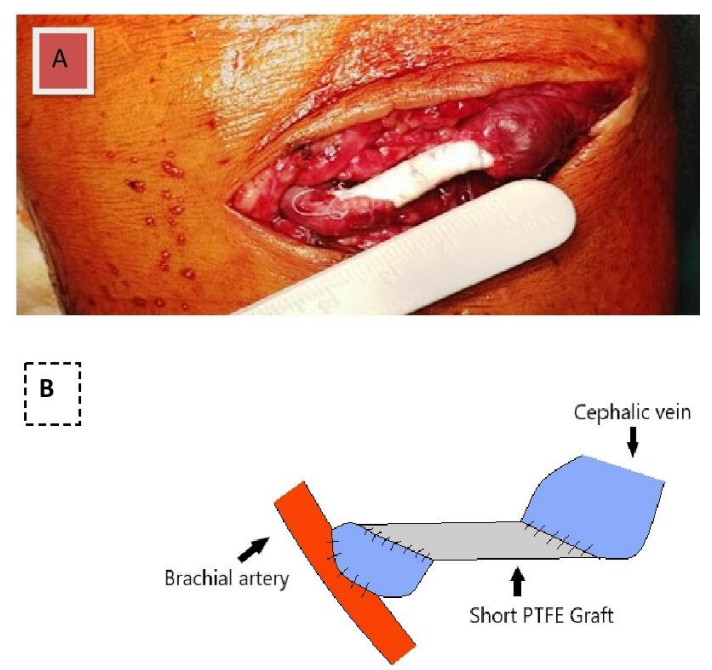

Figure 1 (A) A short polytetrafluoroethylene (PTFE) graft was inserted into the outflow vein beyond the anastomosis of a left brachiocephalic fistula at the elbow. (B) Schematic representation. between the diameters, the anastomoses were created obliquely and performed, so that the resulting angles in the anastomoses corresponded to the upward rotation of the cephalic vein. Postoperatively, brachial flow decreased to $1000 \mathrm{~mL} / \mathrm{min}$, the patient's symptoms disappeared and the ulcer eventually healed. Three weeks later, the patient began haemodialysis through the fistula. For the next 7 years, the fistula was used for haemodialysis without recurrence of steal until the patient died of cancer.

A 'steal phenomenon' is usually present in nearly $80 \%$ of arteriovenous accesses (AVAs), but patients remain asymptomatic, mainly because of compensation by dilation of the collateral vessels. This compensation is impaired in the presence of diabetes or atherosclerosis and may lead to 'steal syndrome' in 4\%-8\% of AVAs. In this case, symptoms of distal ischemia occur, ranging from coolness and numbness in the fingers to ischaemic pain or gangrene. Severe symptoms require intervention to resolve the ischemia. Treatment may include several options depending on the flow measurement. Fistulas with a high flow are classically corrected with flow-limiting procedures such as banding or Revision Using Distal Inflow (RUDI) procedures. Fistulas with a normal flow have been treated with Distal RevascularisationInterval Ligation or Proximalisation of Arterial Inflow. ${ }^{1}$ Several additional techniques have been reported in the literature, with ligation being the last option..$^{2-6}$ Prior DSA with correction of critical stenosis is mandatory and can eliminate the steal in many cases. There are little data in the literature on short interposition grafts for the treatment of dialysis access steal syndrome. ${ }^{7}$ The goal is to restrict flow by narrowing the wide vein lumen. In our case, although we interposed a $6 \mathrm{~mm}$ graft, after a month, the diameter would be only $4 \mathrm{~mm}$ because the neointima normally covers the wall. Consequently, we created short stenosis of $4 \mathrm{~mm}$ in a large outflow vein of $12-15 \mathrm{~mm}$, achieving a flow reduction of approximately $60 \%$.

We did not prefer external banding with a PTFE strip around the vein because we were concerned that banding would lead to severe internal folds due to the large vein diameter, which could compromise the longevity of the procedure. In addition, we did not use the RUDI technique because of its complexity. In this case, the fistula is ligated and blood flow is restored with a venous bypass from the proximal radial or ulnar artery. ${ }^{1}$ In conclusion, we believe that our technique represents an 
alternative flow-limiting procedure for the treatment of accessrelated steal syndrome in hyperfunctioning fistulas.

\section{Learning points}

- Dialysis access steal syndrome (DASS) should be promptly recognised and treated before inadvertent ischemia of the hand occurs.

- Reducing the diameter of a wide outflow vein by inserting a short polytetrafluoroethylene (PTFE) graft can normalise blood flow in high-flow brachiocephalic fistulas. This is a simple procedure that does not require intraoperative ultrasound monitoring or fluoroscopic assistance. We believe it has a role in the subset of patients with DASS with highflow brachiocephalic fistulas and a wide outflow vein beyond the anastomosis.

Contributors FM and SP had the idea of the study. FM and TT prepared the manuscript. FM and PD critically revised the manuscript. All authors accepted the final version of the manuscript.

Funding The authors have not declared a specific grant for this research from any funding agency in the public, commercial or not-for-profit sectors.

Competing interests None declared.

Patient consent for publication Consent obtained directly from patient(s)
Provenance and peer review Not commissioned; externally peer reviewed.

Case reports provide a valuable learning resource for the scientific community and can indicate areas of interest for future research. They should not be used in isolation to guide treatment choices or public health policy.

\section{ORCID iD}

Francesk Mulita http://orcid.org/0000-0001-7198-2628

\section{REFERENCES}

1 Shaikh FA, Siddiqui N, Shahzad N, et al. Operative techniques to prevent dialysis Access-associated steal syndrome in high-risk patients undergoing surgery for hemodialysis access: a systematic review. Cureus 2019;11:e6086.

2 Horst VD, Nelson PR, Mallios A, et al. Avoiding hemodialysis access-induced distal ischemia. J Vasc Access 2021;22:786-94.

3 Crane J, Salim S, Storey R. Feasibility of a $3 \mathrm{~mm}$ arteriotomy for brachiocephalic fistula formation. J Vasc Access 2021;22:697-700.

4 Cheun TJ, Jayakumar L, Sideman MJ, et al. Upper extremity arterial endovascular interventions for symptomatic vascular access-induced steal syndrome. J Vasc Surg 2019:70:1896-903.

5 Mohamed AS, Peden EK. Dialysis-associated steal syndrome (DASS). J Vasc Access 2017:18:68-73.

6 Aschwanden M, Hess P, Labs K-H, et al. Dialysis access-associated steal syndrome: the intraoperative use of duplex ultrasound scan. J Vasc Surg 2003;37:211-3.

7 Hashimoto T, Akagi D, Yamamoto S, et al. Short interposition with a small-diameter prosthetic graft for flow reduction of a high-flow arteriovenous fistula. J Vasc Surg 2021;73:285-90.

Copyright 2022 BMJ Publishing Group. All rights reserved. For permission to reuse any of this content visit https://www.bmj.com/company/products-services/rights-and-licensing/permissions/

BMJ Case Report Fellows may re-use this article for personal use and teaching without any further permission.

Become a Fellow of BMJ Case Reports today and you can:

- Submit as many cases as you like

- Enjoy fast sympathetic peer review and rapid publication of accepted articles

- Access all the published articles

- Re-use any of the published material for personal use and teaching without further permission

\section{Customer Service}

If you have any further queries about your subscription, please contact our customer services team on +44 (0) 2071111105 or via email at support@bmj.com.

Visit casereports.bmj.com for more articles like this and to become a Fellow 